\title{
Author Correction: Integrated records of environmental change and evolution challenge the Cambrian Explosion
}

Rachel Wood (D), Alexander G. Liu (D), Frederick Bowyer, Philip R. Wilby (D), Frances S. Dunn, Charlotte G. Kenchington, Jennifer F. Hoyal CuthillD, Emily G. Mitchell D and Amelia Penny

Correction to: Nature Ecology \& Evolution https://doi.org/10.1038/s41559-019-0821-6, published online 11 March 2019.

In the version of this article initially published, the reference "Mitchell, E. G., \& Kenchington, C. G. The utility of height for the Ediacaran organisms of Mistaken Point. Nat. Ecol. Evol. 2, 1218-1222 (2018)." was missing. A callout to the reference should have been placed at the end of this sentence: "For biotic replacement to occur, taxa must be both spatially collocated and have similar resource requirements, yet spatial analyses of contemporary communities find only very limited instances of resource competition." The reference has been added to the list, and the error has been corrected in the PDF and HTML versions of the article. 